\title{
Cervical Cytology Associated with Pelvic Inflammatory Diseases
}

\section{Misra JS, Srivastava AN*, Sharique A and Srivastava KR}

Department of Pathology and Obstetrics and Gynaecology, Era's Lucknow Medical College, Lucknow, India

*Corresponding author: Srivastava AN, Director Research \& Head, Department of Pathology, Era's Lucknow Medical College \& Hospital, Lucknow, Uttar Pradesh, India, Tel: 009415409779; E-mail: ans4csmmu@gmail.com

Rec date: May 14, 2015, Acc date: Jun 25, 2015, Pub date: Jun 27, 2015

Copyright: () 2015 Misra JS, et al. This is an open-access article distributed under the terms of the Creative Commons Attribution License, which permits unrestricted use, distribution, and reproduction in any medium, provided the original author and source are credited.

\begin{abstract}
Objective: The present study was aimed to investigate the incidence of squamous intraepithelial lesions of cervix (SIL), frank cervical cancer and different STDs in 503 women with pelvic inflammatory disease (PID).

Study design: Cytological evolution of cervical smears was carried out in 503 women attending Gynae Outpatient Department of Era's Lucknow Medical College, Lucknow India, between October 2009 and June 2014 who were diagnosed with PID and also during Rural Cervical Cancer Screening in Malihabad and Kakori Block of Lucknow District between May 2013 to April 2015.

Results: The cervical cytology in 503 women with PID showed alarmingly high rate of SIL (144- cases -28.6\%) though 134 of them were of low grade. No case of carcinoma cervix was seen. The incidence of Candida albicans was $4.3 \%$ in these women and only 2 cases of Trichomonal infection were seen. The incidence of SIL was maximum in younger, sexually active women between $21-30$ years after which it declined.

Conclusion: The study revealed a very high incidence of SIL associated with PID. As majority of the women screened were from rural areas, it appears that poor hygiene and persistent infection has led to the high incidence of SIL. Hence urgent need is felt in organizing cytological screening programme in rural region of the country to screen specially the symptomatic women to detect any early onset of cervical precancer, the subsequent treatment of which would check any progression of the disease to malignancy.
\end{abstract}

\section{Introduction}

Pelvic inflammatory disease (PID) is most prevalent in Indian women. The vague pain in the lower abdomen and persistent vaginal discharge are the most frequent symptoms associated with the disease. Era's Lucknow Medical College which is situated at the suburb of Lucknow caters the need of both urban and adjacent rural population and hence the women attending Gynae OPD are mixed cohorts of urban and rural women. Routine cytological screening is being carried out at this centre and between a span of more than 4 years (October 2009-June 2014), a total of 162 women were diagnosed with PID. In addition, during Rural Cervical Cancer Screening in the adjacent area of the college, a total of 341 women were diagnosed PID. We thought it is interesting to study the incidence of different cytopathologies and STDs in the total 503 cases diagnosed with PID.

\section{Materials and Methods}

During routine cytological screening at Gynae OPD of Era's Lucknow Medical College Lucknow, and Rural Cervical Cancer Screening a total of 503 women were diagnosed with PID. A detailed clinical history was taken in each case and prior to bimanual examination; a scrape smear was taken from the squamocolumnar junction of the cervix with the help of Ayre's spatula and immediately fixed in absolute alcohol. The smears were stained with Papanicalaous technique and cytologically graded according to the Bethesda system of classification of 2001 [1]. As routine all the cases of HSIL and frank carcinoma were subjected to cervical biopsy. Four different types of STDs were also investigated into these smears namely Trichomonas vaginalis, Candida albicans, Herpes simplex and HPV infection. The Trichomonal and Candidal infection were reported on the individual presence of the pathogen in the smear, while the viral STDs - HPV and HSV were diagnosed on the basis of cytopathological effects (CPE) produced by them in the squamous cells viz. koilocytosis in HPV infection (condyloma) and ground grass appearance of nuclei in the case of HSV infection. Histopathological sections depicting CPE changes associated with mild dysplastic changes (LSIL) alongwith koilocytosis are shown in Figures $1 \mathrm{a}$ and $1 \mathrm{~b}$ and only koilocytosis in Figures $2 \mathrm{a}$ and $2 \mathrm{~b}$.

\section{Results}

Cytological evaluation of cervical smears in 503 women diagnosed with PID revealed following cytopathological changes in the cervix (Table 1).

\begin{tabular}{|l|l|}
\hline Total No. of ASCUS cases & $29(5.7 \%)$ \\
\hline Total no. of SIL cases & $144(28.6 \%)$ \\
\hline Of these following were LSIL & $134(26.6 \%)$ \\
\hline (a). Mild dysplasia & $131(26.1 \%)$ \\
\hline (b). Condyloma (HPV infection) & $3(0.5 \%)$ \\
\hline HSIL & $10(1.9 \%)$ \\
\hline
\end{tabular}

Table 1: Cytological evaluation of cervical smears. 
Citation: Misra JS, Srivastava AN, Sharique A, Srivastava KR (2015) Cervical Cytology Associated with Pelvic Inflammatory Diseases. J Cytol
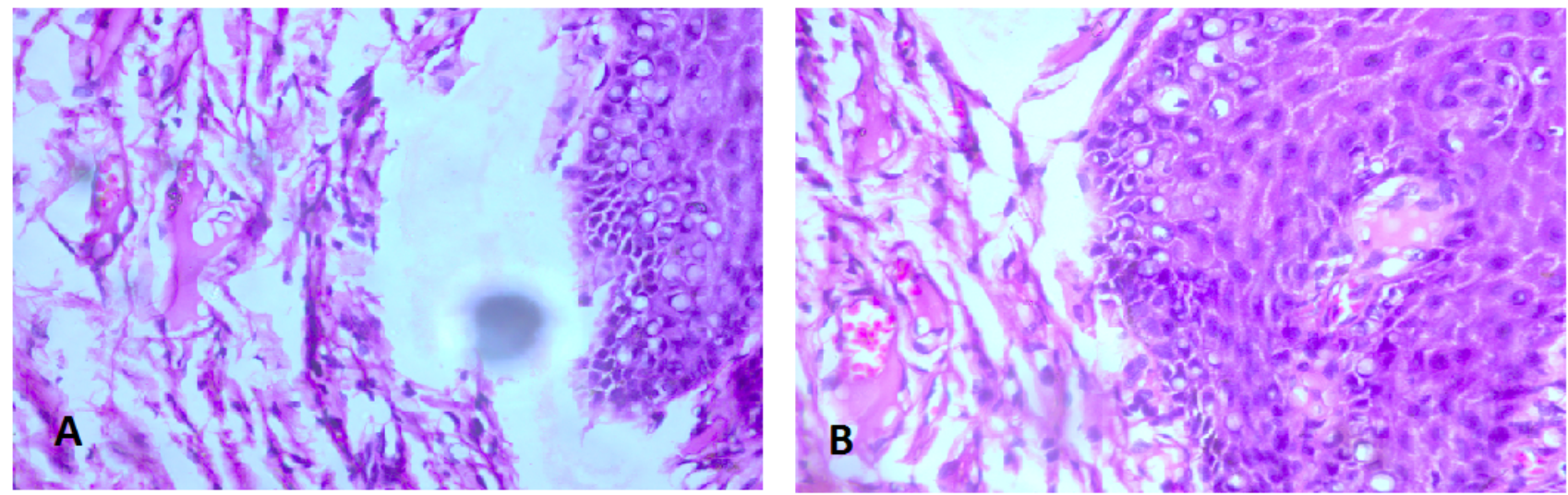

Figure 1a and b: Histological section of cervix showing mild dysplastic changes (LSIL) along with koilocytosis in large number of squamous cells. Note a large clear vacuole replacing the whole cytoplasm of the cell. The nucleus is enlarged, hyperchromatic with coarse chromatin.

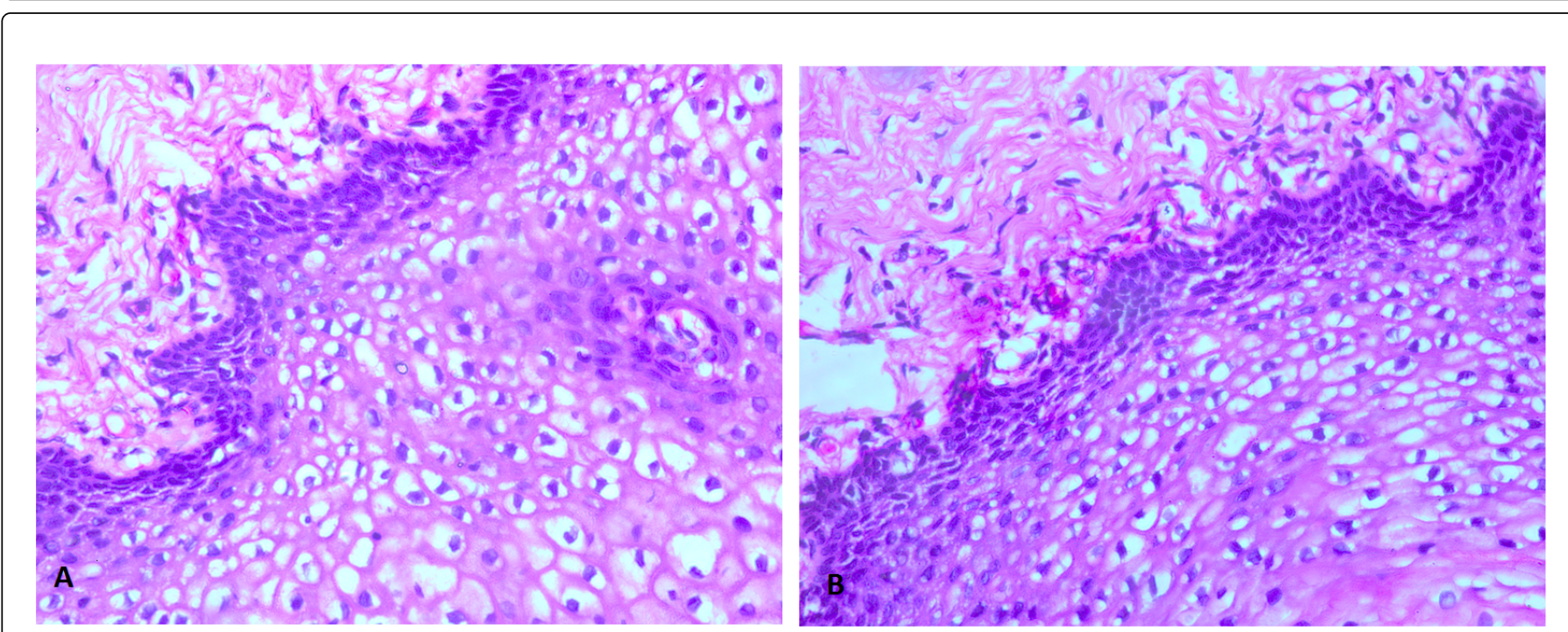

Figure 2a and b: Histological section of cervix showing koilocytosis in large number of squamous cells. Note large clear vacuoles replacing the whole cytoplasm of the cell. The nuclei are irregular, contracted and hyperchromatic.

No case of frank carcinoma was seen.

The incidence of SIL was alarmingly high with PID (28.6\%) though majority of these cases were LSIL $(26.6 \%)$

Though marked Cocobacilli infection was seen in almost $30 \%$ of the 503 women showing PID but this is normal finding with this disease. However, following two types of STDs were seen in the cervical smears of 503 women with PID.

\section{Candida albicans: 22 (4.3\%)}

Trichomonas vaginalis: $2(0.3 \%)$

The incidence of Candida was high with PID as compared to Tricomonal infection. The infection of Candida was associated with 9 of the 131 mild dysplasia cases $(6.8 \%)$.
The incidence of SIL and two STDs were analyzed in different age groups of 503 women with PID and is shown in Table 2.

The incidence of SIL was maximum in younger women up to 30 years after which it relatively declined with increasing age but, on the whole, remained very high even beyond 30 years of age. The incidence of Candida was also high in younger sexually active women up to 30 years and remained higher even with increasing age. There were 2 cases of Trichomonas infection and it was seen in younger women between $21-30$ years (1.1\%).

\section{Discussion}

Cytological evaluation of cervical smears in 503 women diagnosed with PID showed alarmingly high incidence of $28.6 \%$ of SIL though majority of them were of low grade. The incidence of Candida albicans 
was $4.3 \%$ in these women. As the majority of screen women of the college were from the rural areas, it appears that poor hygiene and persistence of the infection left untreated has led to high incidence of SIL in these PID cases.

\begin{tabular}{|l|l|l|l|l|}
\hline Age group & $\begin{array}{l}\text { No. } \\
\text { cases }\end{array}$ & $\begin{array}{l}\text { No. of cases } \\
\text { showing SIL }\end{array}$ & $\begin{array}{l}\text { No. of } \\
\text { cases } \\
\text { showing } \\
\text { Candida } \\
\text { albicans }\end{array}$ & $\begin{array}{l}\text { No. of cases } \\
\text { showing } \\
\text { Trichomonal } \\
\text { vaginalis }\end{array}$ \\
\hline Below 20 years & 11 & $2(18.1 \%)$ & $2(18.1 \%)$ & - \\
\hline $21-30$ years & 190 & $57(30.0 \%)$ & $8(4.2 \%)$ & $2(1.05 \%)$ \\
\hline $31-40$ years & 194 & $45(23.1 \%)$ & $6(3.1 \%)$ & - \\
\hline Above 40 years & 108 & $30(27.7 \%)$ & $6(5.5 \%)$ & - \\
\hline
\end{tabular}

Table 2: Incidence of SIL and STD in different age groups of 503 women showing PID.

In a similar study in Nigeria, Abdul et al. [2] have reported a $14 \%$ incidence of CIN in patients with chronic PID. In another study, Giraud et al. [3] have found CIN more frequent (14.02\%) in women under treatment for PID. Singh et al. [4] have reported a case of metastatic cervical cancer in PID case with HIV and have suggested that coexistent pelvic infection may contribute to the development and spread of the cervical cancer [4]. However, no case of frank carcinoma was seen in the present series.

In an Indian study involving cervical cytology in unhealthy cervix, Verma et al. [5] have found $10.7 \%$ of SIL in women complaining of vaginal discharge and pain in lower abdomen [5]. Earlier Das et al. [6] have also reported similar findings.

In a 35 years hospital based cytological screening at Queen Mary's Hospital of K.G Medical University Lucknow, India. Misra et al. [7] have evaluated cervical smears in a total of 36-484 women and have found an overall incidence of $7.8 \%$ of SIL [7]. The incidence of SIL in women complaining of vague pain in lower abdomen and vaginal discharge was low to the tune of $8.5 \%$. Trichomonal infection was the most common STD seen in these women (6.6\%). As majority of these screened women were from the urban setup, it appear that the adequate hygiene and treatment of infection whenever detected has led to the low incidence of SIL in these women. The incidence of Candida was very low in urban women $(2.1 \%)$ in contrast to $4.3 \%$ seen in the present series. As the majority of women screened presently were from rural areas, there is great variation in the incidence of different STDs in the urban and rural setup. As the incidence of SIL is very high in the presently screened women, it appears that poor hygiene and persistent of infection has led to the high incidence of SIL in these women, Hence the study points out the urgent need of organizing cytological screening programme in the villages of our country to cover all women as much as possible and should be made mandatory in symptomatic women especially those with PID. This will result in detection in large number of SIL cases and STD infection the adequate treatment of which will bring down the incidence of carcinoma cervix in rural women.

\section{Conclusion}

The cytological examination of 503 women diagnosed with PID revealed a high incidence of SIL though the 2 STDs seen (Candida albicans and Trichomonas vaginalis) were not found in high number ( $4.3 \%$ and $1.1 \%$ respectively). As majority of women screened were from rural, setup where the women practice poor hygiene which may cause the persistence of infection, it appears that these might be the causative factors for high prevalence of SIL in these women. Hence necessity is felt to organize educational activities in rural areas to create awareness regarding the hazards of cervical cancer and need for maintaining a good personal hygiene. Also an urgent need for regular cytological screening is felt in these women to detect early cases of carcinoma cervix, the treatment of which will check any progression to cervical cancer and will thus reduce their miseries.

\section{Acknowledgements}

The authors are thankful to the secretary, Era's Educational Trust and the management of Era's Lucknow Medical College and Hospital, Lucknow, India for financially supporting this Intramural Research Project.

\section{References}

1. Solomon D, Davey D, Kurman R, Moriarty A, O'Connor D, et al. (2002) The 2001 Bethesda System: terminology for reporting results of cervical cytology. JAMA 287: 2114-2119.

2. Abdul MA, Shittu SO, Randawa JA, Shehu MS (2009) The cervical smear pattern in patients with chronic pelvic inflammatory disease. Niger J Clin Pract 12: 289-293.

3. Giraud J, Coiffic J, Poulain P, Kerisit J (1998) High prevalence of cervical intra-epithelial neoplasia in women treated for pelvic inflammatory disease. Eur J Obstet Gynecol Reprod Biol 81: 51-54.

4. Singh GS, Aikins JK, Deger R, King S, Mikuta JJ (1994) Metastatic cervical cancer and pelvic inflammatory disease in an AIDS patient. Gynecol Oncol 54: 372-376.

5. Verma I, Jain V, Kaur T (2014) Application of bethesda system for cervical cytology in unhealthy cervix. J Clin Diagn Res 8: OC26-30.

6. Das S, Mishra G, Panda S (1984) Evaluation of cytology in unhealthy cervix. J Indian Med Assoc 82: 166-170.

7. Misra JS, Srivastava S, Singh U, Srivastava AN (2009) Risk-factors and strategies for control of carcinoma cervix in India: hospital based cytological screening experience of 35 years. Indian J Cancer 46: 155-159. 